http://jmscr.igmpublication.org/home/ ISSN (e)-2347-176x ISSN (p) 2455-0450

crossref DOI: https://dx.doi.org/10.18535/jmscr/v8i2.110

Journal Of Medical Science And Clinical Research

\title{
A Comparative study on staining for Helicobacter Pylori using new triple stain with routine Hematoxylin-Eosin and Giemsa stain
}

\author{
Authors \\ Krishna Sruthi R P $\mathbf{P}^{\mathbf{1}}$, Preethamol $\mathbf{S}^{\mathbf{2}^{*}}$, Indira $\mathrm{K}^{\mathbf{3}}$ \\ ${ }^{1}$ Resident, Department of MLT, Govt. Medical College, Thiruvananthapuram, Kerala \\ ${ }^{2}$ Assistant Professor, Department of Pathology, Govt. Medical College, Thiruvananthapuram, Kerala \\ ${ }^{3}$ Assistant Professor, Department of MLT, Govt. Medical College, Thiruvananthapuram, Kerala \\ Thiruvananthapuram, Kerala \\ *Corresponding Author \\ Preethamol S
}

\begin{abstract}
Background: Helicobacter pylori, a spiral-shaped bacterium, can be seen in hematoxylin and eosin staining. However, when a low density of Helicobacter pylori and atrophic mucosal change are combined, it becomes difficult to demonstrate the organism. Hence many Pathologists now use Hematoxylin-Eosin plus a second stain for the bacteria. The aim of this study is to develop a New Triple Stain (Carbol Fuchsin/ Alcian Bluel Hematoxylin-Eosin) is suitable for simultaneous visualization of Helicobacter pylori and gastric morphology.

Objective: To introduce a New triple stain for simultaneous visualization of gastric morphology and Helicobacter pylori and compare it with routine Hematoxylin-Eosin and Giemsa.

Method: The study was carried out in Histopathology Laboratory and Dept. of MLT in Govt. Medical college Thiruvananthapuram. A total of 47 gastric biopsies confirmed as positive and negative by PCR were included in this study. Each sections from these biopsies stained with Hematoxylin-Eosin, Giemsa and New Triple stain and evaluated by the pathologist.

Result \& Conclusion: The study was aimed to compare Hematoxylin-Eosin, Giemsa and New Triple for the detection of H. pylori. Morphological details are well observed in Hematoxylin-Eosin stain when compared to New Triple stain but bacterial demonstration is poor. Giemsa stain shows poor morphology when compared to both Hematoxylin-Eosin and New Triple Stain but bacterial identification is superior to Hematoxylin-Eosin. Hence it can only be used as a special stain for H.pylori. In histopathological aspect New Triple Stain shows greater sensitivity followed by Giemsa \& Hematoxylin-Eosin.

Keywords: PCR, Hematoxylin-Eosin, Giemsa, New Triple Stain.
\end{abstract}

\section{Introduction}

Helicobacter pylori, is a gram-negative spiral bacterium, which colonizes the gastric epithelium. Infection by Helicobacter pylori has been established as a major cause of chronic gastritis .In India the most common manifestation of $\mathrm{H}$. pylori infection is peptic ulcer disease. H. pylori was considered as a Class I (Definite) carcinogen by International Agency for Research on Cancer (IARC), a subordinate organization of WHO in 1994, based on epidemiological data $.70 \%$ of gastric adenocarcinomas and most gastric MALT lymphomas are related to chronic infection with this organism. The accurate detection of $\mathrm{H}$. pylori 
is essential for managing infected patients and for eradicating the bacteria

Histopathological examination remains the gold standard for the identification, because along with the organism it is possible to identify various pathogenic changes associated with this such as inflammation, intestinal metaplasia, atrophy and malignancy. But when a low density of Helicobacter pylori and atrophic mucosal change are combined, it becomes difficult to demonstrate the organism by routine hematoxylin and eosin staining. As a result, many Pathologists now use a special stain for better demonstration of the bacteria. Several special stains are available for detecting the presence of H.pylori in gastric biopsies which include Giemsa, Warthin Starry or Steiner silver stains, Toluidine blue method, Genta staining, Gimenez method, Fluorescent staining and Immunohistochemistry staining. Several studies have been conducted about the need for use of special stains in H.pylori detection .The present study where conducted to develop a New Triple Stain (CarbolFuchsin/ Alcian Blue/ Hematoxylin-Eosin) which has an added advantage of simultaneous visualization of Helicobacter pylori along with gastric morphology.

\section{Objective}

To introduce a new triple stain for simultaneous visualization of gastric morphology and Helicobacter pylori and compare it with routine Hematoxylin-Eosin and Giemsa.

\section{Methodology}

This is a comparative study in which 47 formalin fixed Gastroduodenal biopsy samples were collected from Department of Medical Gastroenterology, Government Medical College, Thiruvananthapuram and the samples were analysed at Histopathology Laboratory, Department of Pathology, Government Medical College, Thiruvananthapuram. After obtaining clearance from the Institutional Ethics Committee. The slides prepared from paraffin blocks of the specimens were stained with the conventional hematoxylin and eosin method and a preliminary scanning was done to include all well-preserved specimens and exclude all inadequate, tissue sections with necrotic material, under fixed and showing processing artefacts.

The slides prepared from paraffin blocks of the specimens were cut at $4 \mu \mathrm{m}$ thick sections and stained with the conventional hematoxylin and eosin stain ,giemsa stain and the New Triple stain (a combination of Carbol fuchsin, Alcian blue hematoxylin and Eosin). Stained sections were evaluated and scored by Pathologist based on the 5 parameters- (Table 1) morphology, staining quality, differentiation, background staining and identification of bacteria. After that comparison of test sensitivities and specificities for $\mathrm{H}$. pylori in Gastric biopsy.

\section{Result}

The present study included the comparison of Hematoxylin-Eosin Giemsa and New Triple Stain for the detection of $\mathrm{H}$. pylori on 47 gastric biopsies which are PCR confirmed positive and negative for H.pylori infection. In addition to the bacterial detection, staining quality, background, morphology and differentiation were analysed. With a view of analysing the results, the evaluation of pathologist was tabulated.

Out of 47 slides morphology is excellent for 28 slides, satisfactory for 17 slides and poor for 2 slides in case of Hematoxylin-Eosin staining. In case of Giemsa staining 16 slides were satisfactory and 31 slides show poor morphology. In New Triple Stain, 12 slides show excellent morphology were 30 satisfactory morphology and 5 poor morphology. The observed measure of agreement for the clarity of morphology between Hematoxylin-Eosin versus Giemsa is 0.128 , which is slight, Hematoxylin-Eosin versus New Triple is 0.34 , which is fare and Giemsa versus New Triple stain is 0.135 which is also slight. (Graph 1)

Out of 47 slides differentiation is excellent for 35 slides, satisfactory for 10 slides and poor for 2 slides in case of Hematoxylin-Eosin staining. In 
case of Giemsa staining 5 slides were satisfactory and 42 slides show poor differentiation. In New Triple Stain, 15 slides show excellent differentiation were 23 satisfactory differentiation and 9 shows poor differentiation. The observed measure of agreement for the differentiation between Hematoxylin-Eosin versus Giemsa is 0.003 , which is slight, Hematoxylin-Eosin versus New Triple stain is 0.116 , which is also slight and Giemsa versus New Triple stain is 0.178 which is also slight. (Table 2)

Out of 47 slides staining quality was excellent for 27 slides, satisfactory for 17 slides and poor for 3 slides in case of Hematoxylin-Eosin staining. In case of Giemsa staining 10 slides shows excellent staining quality 28 slides were satisfactory and 9 slides show poor staining quality. In New Triple Stain, 21 slides show excellent staining quality 21 satisfactorily stained and 5 poorly stained. The observed measure of agreement for staining quality between Hematoxylin-Eosin versus Giemsa is 0.345 , which is slight, HematoxylinEosin versus New Triple stain is 0.704 , which is substantial and Giemsa versus New Triple stain is 0.449 which is moderate. (Graph 2)

Out of 47 slides background staining was excellent for 23 slides, satisfactory for 19 slides and poor for 5 slides in case of HematoxylinEosin staining. In case of Giemsa staining 18 slides shows excellent background staining, 22 slides were satisfactory and 7 slides shows poor background staining. In New Triple Stain, 20 slides show excellent background staining 22 satisfactorily stained and 5 poorly stained. The observed measure of agreement for background staining between Hematoxylin-Eosin versus Giemsa is 0.000, which is slight, HematoxylinEosin versus New Triple stain is 0.499 , which is moderate and Giemsa versus New Triple stain is 0.000 which is slight. (Table 3)

Out of 47 biopsies, 24 biopsies show positive results and 23 biopsies shows negative results in PCR. Among this 47 cases H. pylori was not detected in any slides stained with HematoxylinEosin. so Hematoxylin-Eosin doesn't show any significance in this study. But no false positive result hence it shows $100 \%$ specificity. In Giemsa staining H.pylori detected in 2 cases and hence it has a sensitivity of $12.5 \%$ and specificity of $100 \%$ when compared to that of PCR. In New Triple Staining H. pylori detected in 8 cases and it has a sensitivity of $33.3 \%$ and specificity of $100 \%$ when compared to that of PCR. (Graph 3)

Table 1 Criteria of assessments parameters

\begin{tabular}{|l|c|c|c|}
\hline Assessment parameters & \multicolumn{3}{|c|}{ Score given as per mentioned criteria } \\
\cline { 2 - 4 } & 1 & 2 & 3 \\
\hline 1.Staining quality & $\begin{array}{c}\text { Not stained, unevenly } \\
\text { stained, has artefacts }\end{array}$ & $\begin{array}{c}\text { Details not visualized but } \\
\text { suitable for diagnosing }\end{array}$ & $\begin{array}{c}\text { Good contrast, visibility of } \\
\text { details, brilliant staining }\end{array}$ \\
\hline 2. Background & Not clear, lot of deposits & $\begin{array}{c}\text { Moderate deposit but } \\
\text { suitable to study }\end{array}$ & $\begin{array}{c}\text { Clear background, no } \\
\text { interference }\end{array}$ \\
\hline 3. Morphology & $\begin{array}{c}\text { Not preserved, detached } \\
\text { from slide }\end{array}$ & Moderately preserved & $\begin{array}{c}\text { Good preservation of } \\
\text { tissue architecture }\end{array}$ \\
\hline 4. Differentiation & $\begin{array}{c}\text { Specific components not } \\
\text { seen clearly }\end{array}$ & $\begin{array}{c}\text { Specific components are } \\
\text { seen well but in some area } \\
\text { difficult to appreciate }\end{array}$ & $\begin{array}{c}\text { Specific components seen } \\
\text { clearly and appreciated } \\
\text { very well }\end{array}$ \\
\hline 1-Poor 2- satisfactory & 3- excellent & \multicolumn{2}{|c|}{}
\end{tabular}

Table no: 2Comparison of differentiation

\begin{tabular}{|l|c|c|c|c|c|c|}
\hline \multirow{2}{*}{ Screening pattern } & \multicolumn{6}{|c|}{ Differentiation } \\
\cline { 2 - 7 } & \multicolumn{2}{|c|}{ H\&E } & \multicolumn{2}{c|}{ Giemsa } & \multicolumn{2}{c|}{ New Triple Stain } \\
\cline { 2 - 7 } & $\mathrm{N}$ & $\%$ & $\mathrm{~N}$ & $\%$ & $\mathrm{~N}$ & $\%$ \\
\hline Poor & 2 & 4.3 & 42 & 89.4 & 9 & 19.1 \\
\hline Satisfactory & 10 & 21.3 & 5 & 10.6 & 23 & 48.9 \\
\hline Excellent & 35 & 74.5 & 0 & 0 & 15 & 31.9 \\
\hline Total & 47 & 100.0 & 47 & 100.0 & 47 & 100.0 \\
\hline
\end{tabular}


Table no: 3 Comparison of Background staining

\begin{tabular}{|l|c|c|c|c|c|c|}
\hline \multirow{3}{*}{ Screening pattern } & \multicolumn{6}{|c|}{ Background } \\
\cline { 2 - 7 } & \multicolumn{2}{|c|}{ H\&E } & \multicolumn{2}{c|}{ Giemsa } & \multicolumn{2}{c|}{ New Triple Stain } \\
\cline { 2 - 7 } & $\mathrm{N}$ & $\%$ & $\mathrm{~N}$ & $\%$ & $\mathrm{~N}$ & $\%$ \\
\hline Poor & 5 & 10.6 & 7 & 14.9 & 5 & 10.6 \\
\hline Satisfactory & 19 & 40.4 & 22 & 46.8 & 22 & 46.8 \\
\hline Excellent & 23 & 48.9 & 18 & 38.3 & 20 & 42.6 \\
\hline Total & 47 & 100.0 & 47 & 100.0 & 47 & 100.0 \\
\hline
\end{tabular}

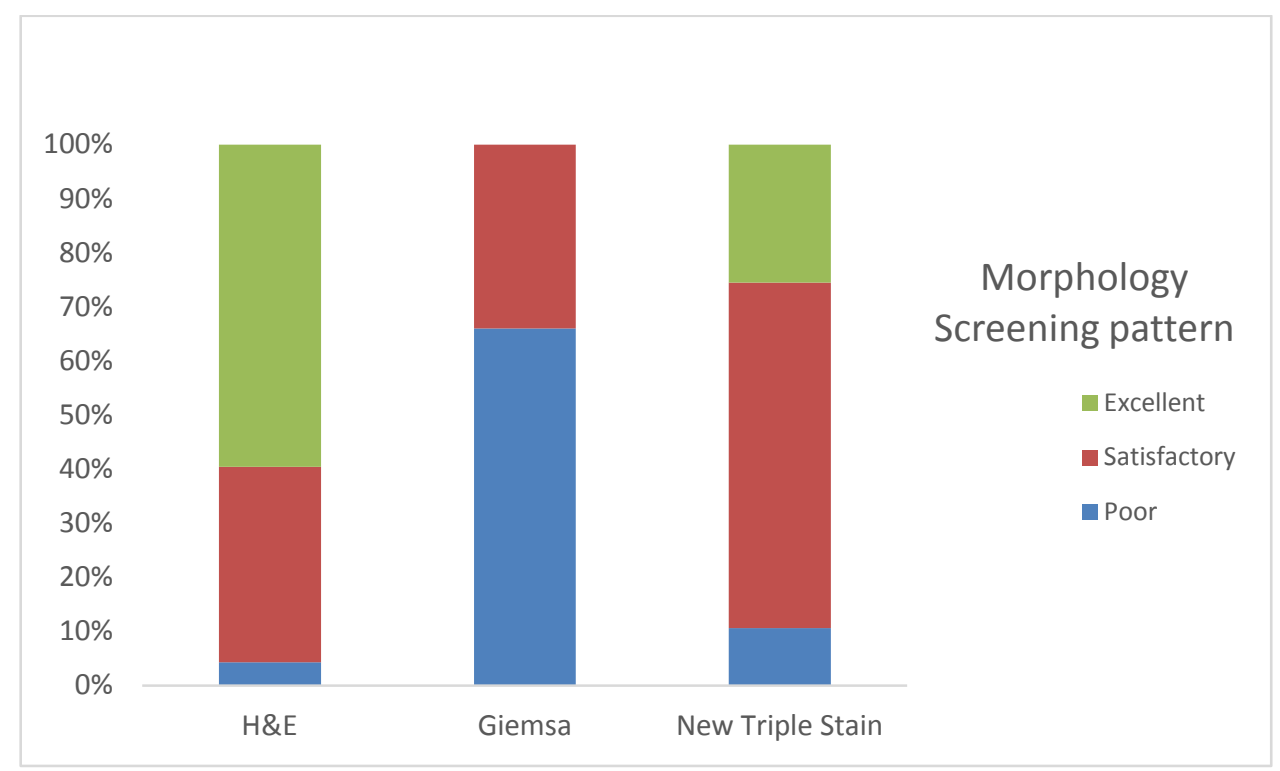

Graph No: 1 Comparison of morphology

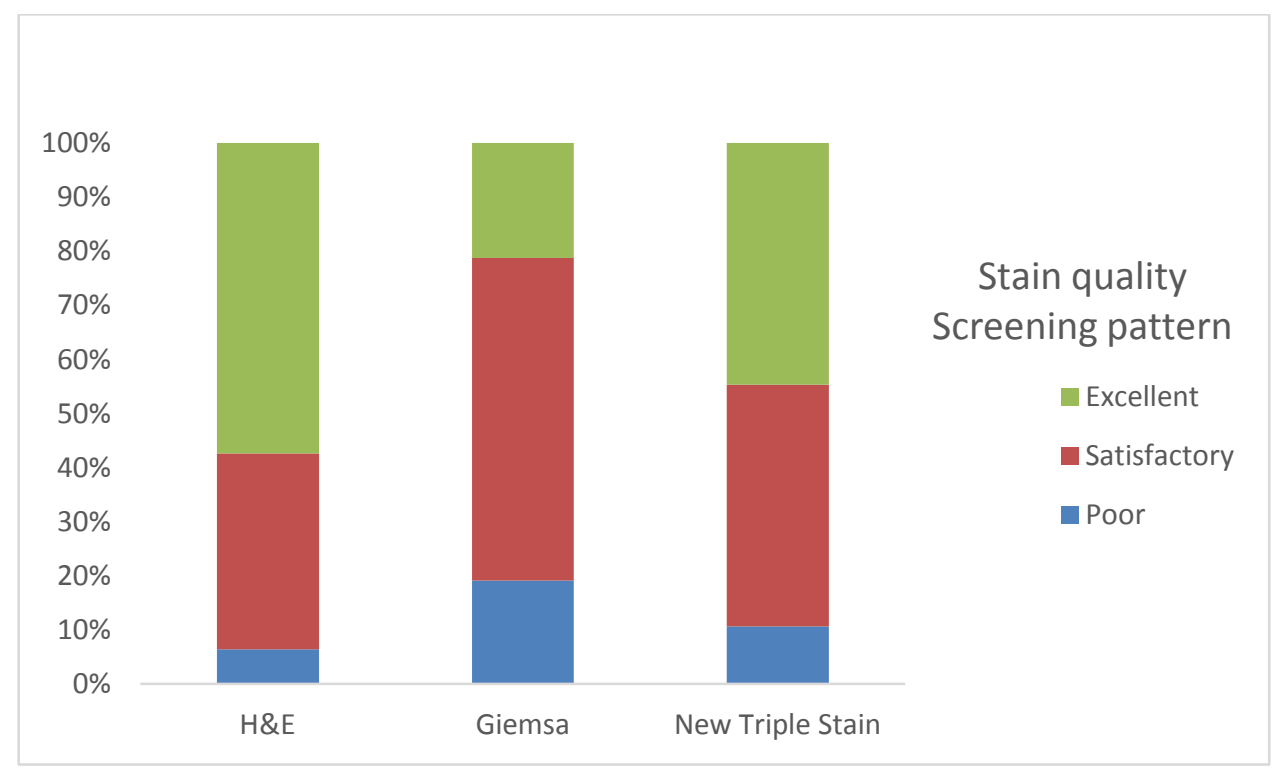

Graph No: 2 Comparison of staining quality 


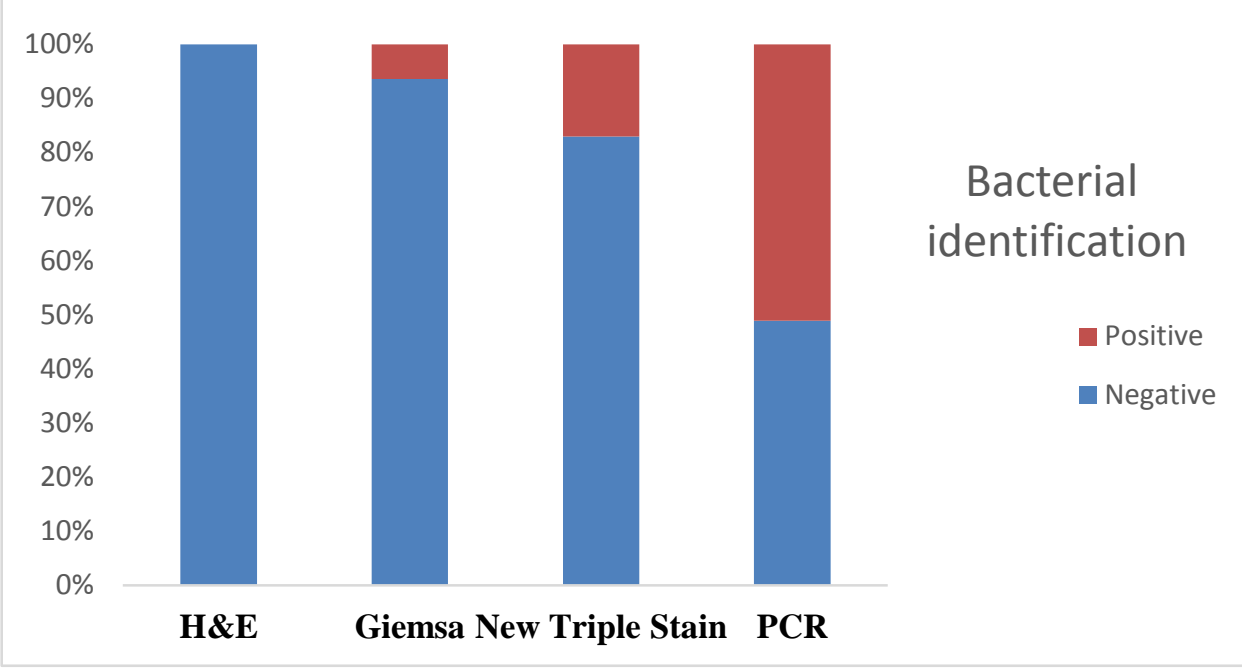

Graph No:3 Comparison of bacterial identification

Fig: 1 Morphology of Gastric Tissue

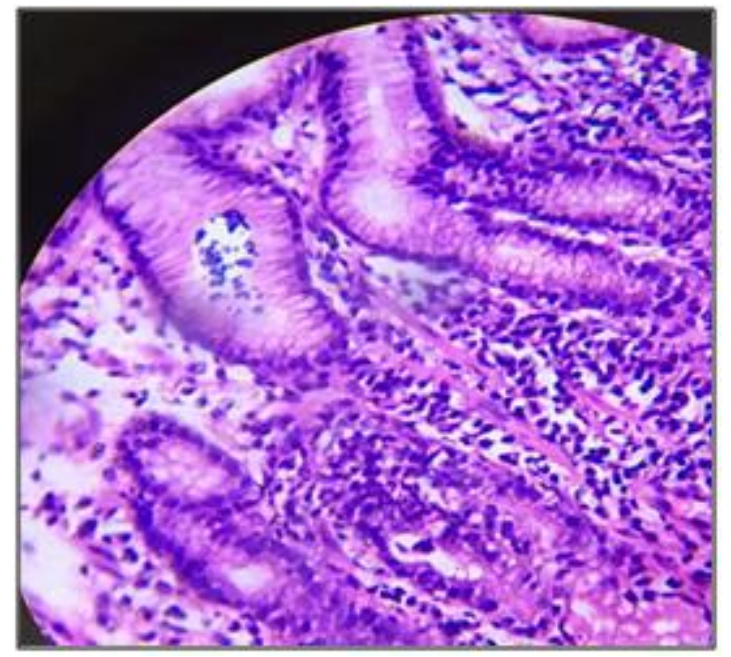

A: H \& E 40X

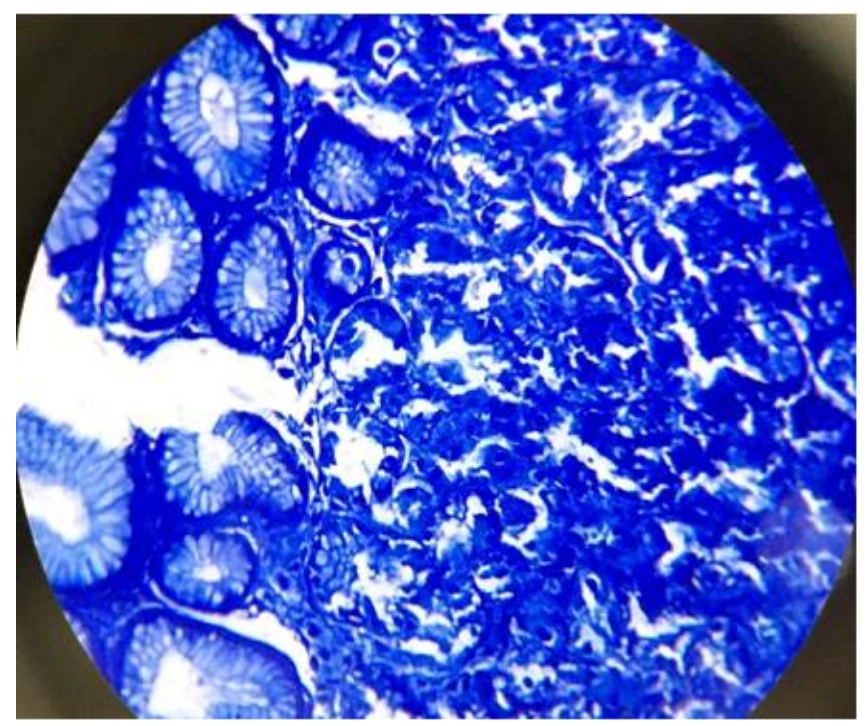

B: Giemsa 40 X

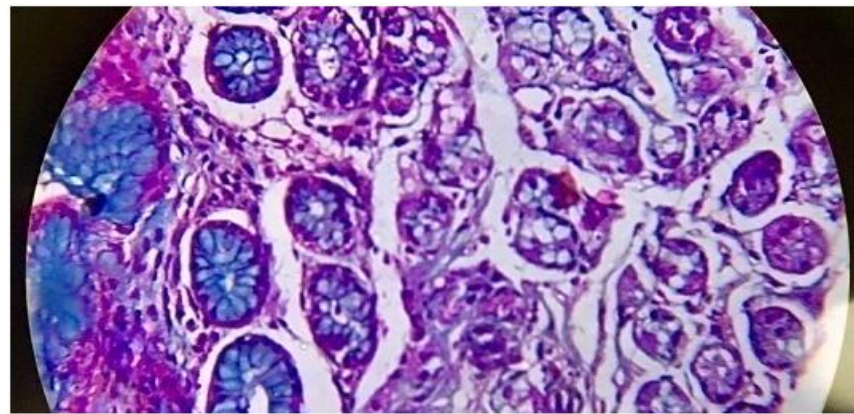

C: New Triple Stain $40 \mathrm{X}$

Fig 2 Bacterial Identification in Gastric Tissue

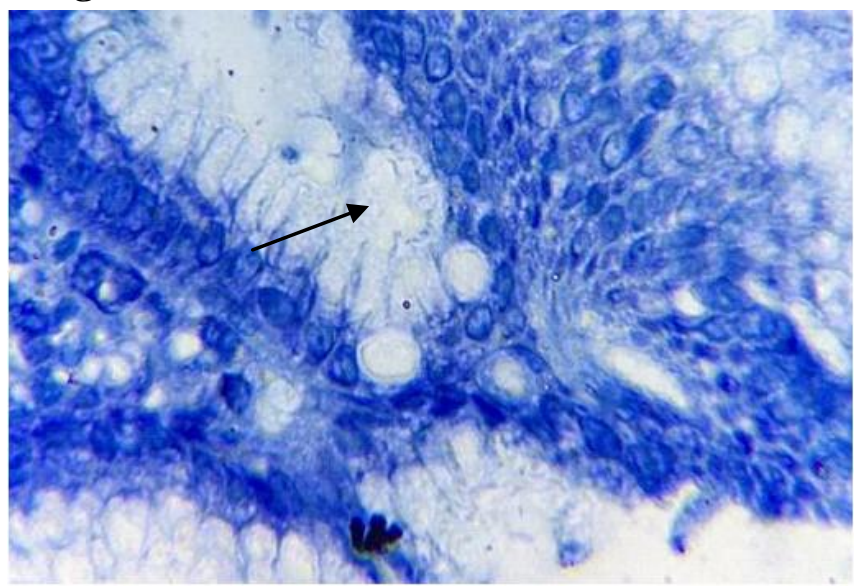

A : Giemsa 100 X 


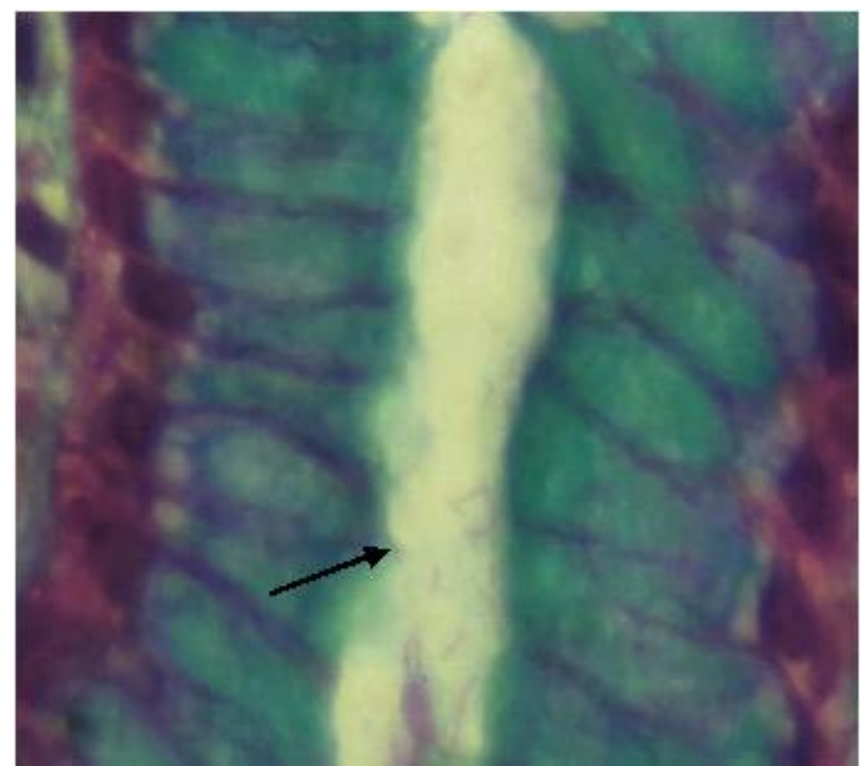

B: New Triple Stain $100 \mathrm{X}$

\section{Discussion}

Helicobacter pylori infection has an important role in the aetiology of several diseases of the gastrointestinal tract which include chronic active gastritis, peptic ulcer, Gastric adenocarcinoma and Mucosa - associated lymphoid tissue lymphoma ${ }^{1}$. It affects more than $50 \%$ of the world wide human population $^{2}$.

The availability of an array of diagnostic methods for the identification of H.pylori denotes the incompetency of any one test to pinpoint the diagnosis. Non-invasive diagnostic tests included urea breath test, stool antigen test and serology ${ }^{3}$. Invasive tests include endoscopy, histology, rapid urease test, culture, and molecular methods ${ }^{4}$.

Serological tests based on the detection of antiH.pylori Ig $\mathrm{G}$ antibody are available for $\mathrm{H}$. pylori detection $^{5}$. The problem with serological test is that it do not differentiate between active infection and past exposure to $\mathrm{H}$. pylori because even after successful eradication antibody levels remain in the blood for longer time. .

Rapid Urease Test is highly specific (95-100\%), economical, simple and rapid method. More than 10,000 bacteria are required for a positive diagnosis. Drug intake can result in false negative results. Other urease producing bacteria in the stomach causes false positive. Culture is the highly specific method for detection of $\mathrm{H}$. pylori infection, but the sensitivity varies widely depending on the quality and transport of specimens, exposure to aerobic environment, technical errors etc. It is also used in population with high antibacterial resistance ${ }^{7}$.

PCR is now used for the diagnosis of $\mathrm{H}$. pylori not only from gastric biopsy specimens, also from saliva, gastric juice, stool etc ${ }^{3}$. It has higher senssitivity and specificity compared to other conventional tests. Advantages of PCR include, positive result even if fewer bacteria are present in the sample, faster results and no need for special processing or transportation. Test material for RTPCR can be taken from tissue in paraffin blocks. Also, PCR detects specific mutations and virulence factors, such as CagA and VacA. This helps to understand the variation in clinical presentation with different strains of $\mathrm{H}$. pylori. Many studies demonstrated that the presence of virulence factors, such as CagA and VacA gene, are associated with severe inflammation of the gastric mucosa and higher prevalence of peptic ulcer disease and gastric cancer. PCR also detect H. pylori in environmental samples for epidemiological studies ${ }^{8}$.

Histology is considered to be the gold standard for direct demonstration of $\mathrm{H}$. pylori infection and is also the first method used for the detection of H.pylori ${ }^{6}$. But, the accurate diagnosis is influenced by various factors like site, size and number of biopsies, staining methods, intake of proton pump inhibitor (PPI) and antibiotics and expertise of the pathologist. Several stains were described for the better identification of the organism other than the routine HematoxylinEosin stain including Warthin- starry stain used originally by Marshall and Warren, Genta, silver stain, toluidine blue, acridine orange, McMullen, Dieterle and immunohistochemical stains. Warthin-Starry stain is expensive and the results not always reliable. Genta stain is a combination of silver, Hematoxylin-Eosin, and Alcian blue stains which identifies the inflammatory cells and $\mathrm{H}$. pylori. But it is time-consuming, complex and expensive method ${ }^{9}$. 
The significance of using ancillary techniques is more important nowadays due to the widespread use of proton pump inhibitors, which can cause reduction in the number and change in the morphology of $\mathrm{H}$ pylori, the organism colonizing proximal stomach, that too in deeper layers. Ancillary techniques especially Immunohistochemistry showed near 100\% sensitivity and specificity in many studies. But cost effectiveness of it is still under debate, especially in developing countries. So it's use is usually limited to those biopsy specimens which show moderate and severe chronic gastritis, but no H. pylori identified in H\&E and special staining ${ }^{10}$. In the present study, 47 gastric biopsies were taken, in which 24 slides were PCR confirmed positive and 23 slides were PCR confirmed negative for $\mathrm{H}$. pylori. The slides were stained with Hematoxylin-Eosin, Giemsa and New Triple Stain. The Pathologist evaluated the staining quality, background, morphology and differentiation with a grading criteria Excellent, satisfactory and poor and the presence of bacteria. From the assessment by the pathologist, our present study shows morphology better in Hematoxylin-Eosin when compared to Giemsa and New Triple stain. Measurement of agreement shows that new triple is fare when compared to Hematoxylin-Eosin, but Giemsa shows poor clarity of morphology.

The present study shows better background in Hematoxylin-Eosin when compared to Giemsa and New Triple stain.

Also shows that the staining quality better in Hematoxylin-Eosin when compared to Giemsa and New Triple stain. Measurement of agreement shows that New Triple stain shows moderate results when compared to Hematoxylin-Eosin, but Giemsa shows poor clarity of morphology.

Out of 47 biopsies, 24 biopsies show positive results and 23 biopsies shows negative results in PCR. Among this 47 cases H. pylori was not detected in any slides stained with HematoxylinEosin. so Hematoxylin-Eosin doesn't show any significance in this study. But no false positive result hence it shows $100 \%$ specificity. In Giemsa staining H.pylori detected in 2 cases and hence it has a sensitivity of $12.5 \%$ and specificity of $100 \%$ when compared to that of PCR. In New Triple Staining H. pylori detected in 8 cases and it has a sensitivity of $33.3 \%$ and specificity of $100 \%$ when compared to that of PCR. Thus New Triple Stain shows greater sensitivity followed by Giemsa and Hematoxylin-Eosin in bacterial identification

\section{Conclusion}

From this study we conclude that even though morphological details are well observed in Hematoxylin-Eosin stain, bacterial demonstration was poor. Giemsa shows poor morphological details but bacterial identification is superior to $H \& E$ and can only be used as a special stain for H.pylori. New Triple Stain shows greater sensitivity followed by Giemsa for H.pylori demonstration, but the morphology is better demonstrated than Giemsa. The major advantage when compared to other methods is that the New Triple stain identifies several pathological changes in gastric mucosa associated with $\mathrm{H}$. pylori infection along with the demonstration of the same.

\section{References}

1. Eurogast Study Group. 1993. An international association between Helicobacter pylori infection and gastric cancer. Lancet, 341, 1359-62.

2. Kasper D, Fauci A, Hauser S, Longo D, Jameson J, Loscalzo J. Harrison's Principles of Internal Medicine. Star. 2015;2958.

3. Vaira, D. and Vakil, N. 2001. Blood, urine, stool, breath, money and Helicobacter pylori. Gut, 48, 287-9.

4. Madan, E., Kemp, J., et al. 1988. Evaluation of staining methods for identifying Campylobacter pylori. Am J ClinPathol, 90, 450-3.

5. Hirschl, A.M., Rathbone, B.J., et al. 1990. Comparison of ELISA antigen 
preparations alone or in combination for serodiagnosing Helicobacter pylori infections. J ClinPathol, 43, 511-13.

6. Braden B. Diagnosis of Helicobacter pylori infection. BMJ 2012; 344: e828 [PMID: $22368293 \quad$ DOI: 10.1136/bmj.e828]

7. Mamivand M, Shahreza S, Sharifi AH. Evaluation of methods for $H$. pylori detection in PPI consumption using culture, rapid urease test and smear examination. Ann Transl Med 2015; 3: 11 [PMID: $25705643 \quad$ DOI: 10.3978/j.issn.2305-5839.2014.11.16]

8. Diagnosis of Helicobacter pylori infection: Current options and developments, World J Gastroenterol 2015 October 28; 21(40): 11221-11235 ISSN 1007-9327 (print) ISSN 2219-2840 (online)

9. Malfertheiner P, Megraud F, O'Morain CA, Atherton J, Axon AT, Bazzoli F, Gensini GF, Gisbert JP, Graham DY, Rokkas T, El-Omar EM, Kuipers EJ. Management of Helicobacter pylori infection-the Maastricht IV/ Florence Consensus Report. Gut 2012; 61: 646664[PMID: 22491499 DOI: 10.1136/gutjnl-2012-302084].

10. Madan E, Kemp J, Westblom TV, Subik M, Sexton S, Cook J. Evaluation of stain methods for identifying Campylobacter pylori. American Journal Clinical Pathology. 1988;90:450-454. 